\title{
A
}

Acta HealthMedica

Acta HealthMedica (ISSN: 2414-6528)

http://www.ActaHealthMedica.com

Volume 2, Issue 2, April-June 2017, Pages: 179, DOI: http://dx.doi.org/10.19082/ah179

\section{EAST AZERBAIJAN POPULATION BASED CANCER REGISTRY DURING 2015 TO 2016: PRELIMINARY REPORT}

\author{
Mohammad Hossein Somi ${ }^{1}$, Roya Dolatkhah ${ }^{2 *}$, Sepideh Sepahi, Mina Belalzadeh, Leila Abdollahi, Azin
} Nahvijoo ${ }^{3}$, Saeed Nemati ${ }^{3}$, Kazem Zendehdel ${ }^{3}$

1. Liver and Gastrointestinal Diseases Research Center, Tabriz University of Medical Sciences, Tabriz, Iran

2. Hematology and Oncology Research Center, Tabriz University of Medical Sciences, Tabriz, Iran

3. Cancer Research Center, Cancer Institute of I.R. Iran, Tehran University of Medical Sciences, Tehran, Iran

Correspondence:

Roya Dolatkhah, Tel: +98 4133361358, Fax:+984133343844, E-mail: royadolatkhah@yahoo.com

\section{TYPE OF ARTICLE: CONFERENCE ABSTRACT}

\begin{abstract}
Introduction: The cancer registry programs provide reliable information on cancer data for evidencebased scientific cancer research. The National Pathology Cancer Registry Program started in 2001 in East Azerbaijan province. However, it led to an underestimated rate for cancer incidence in this region. A population based study was conducted from March 2006 through March 2007, and provide incidence rates for all cancer types. We launched the second East Azerbaijan Population Based Cancer Registry (EAPBCR) program in 2015 and collected data from 20 counties, 62 cities, 44 districts and an area of $45,637.35 \mathrm{~km}^{2}$, with a total population of 3,724,011 according to the 2011 census report of Iran.

Methods: CanReg5 were used for data entry, storage, quality check and analysis of cancer registry data. EAPBCR collects data from pathology labs (including pathology and cytology reports), medical records in the hospitals, causes of death registry, radiotherapy center, hematology centers and imaging centers, during one solar year (20 March 2015 to 19 March 2016). All morphologic and topographic reports were coded based on ICD-O-3 coding system. Age standardized incidence rates (ASRs) were calculated using Standard World Population 2000, and reported per 100,000 populations. This report is on the preliminary results of about $90 \%$ of our cancer patients.

Results: About $90 \%$ of data are presented here as a preliminary report. A total of 6,248 new cancer cases have been registered recently, by the mean age of 61.68 ( $\pm 17.40 \mathrm{SD})$. Of these, 3,479 cases were male and 2,498 were female, and the male to female ratio was 1.39. Age Adjusted Incidence Rate for all cancer for males was 168.9 , and 113.3 for females per 100,000. The five most common cancers according to ASRs in men were stomach, bladder, colorectal, lung, and prostate cancers, respectively. The five most common cancers in women were breast, stomach, colorectal, esophagus, and thyroid cancers, respectively.

Conclusion: Population based cancer registries provide an unbiased data of cancer burden and incidence changes over years. Our priority is to optimize case findings and data processing to provide a reliable estimate for cancer incidence in this region. The low rate of ASR among females is probably due to missing data from a few sources and optimized results from EAPBCR. Updated results will be provided in the congress.
\end{abstract}

KEYWORDS: Cancer; Registry; ASR; Incidence; Crude rate

\section{Abstracts of First National Congress of Medical Informatics, Mashhad, Iran, February 2017}

(C) 2017 The Authors. This is an open access article under the terms of the Creative Commons Attribution-NonCommercialNoDerivs License, which permits use and distribution in any medium, provided the original work is properly cited, the use is non-commercial and no modifications or adaptations are made. 